\title{
Política pública de formação docente na perspectiva dos professores universitários
}

\author{
Public policy of teacher training on the perspective of university professors \\ Política pública de formación docente en la perspectiva de los profesores \\ universitarios

\section{VALÉRIA MOREIRA REZENDE ROGÉRIA MOREIRA REZENDE ISOBE}

Resumo: $\mathrm{O}$ artigo apresenta resultados de investigação que analisa o Programa Institucional de Bolsa de Iniciação à Docência, tendo como foco o modo como os professores universitários que atuam no Programa o concebem e avaliam enquanto política de formação docente. Os resultados do estudo qualitativo ressaltam como aspecto positivo a aproximação entre universidade e escola enquanto espaços colaborativos de formação, mas sinalizam problemas, entre os quais, dificuldades estruturais, alta rotatividade dos licenciandos e as limitações relacionadas à formação política dos licenciandos. Conclui que o Pibid, como política complementar, pode converter-se em reprodutor das atuais mazelas no campo da formação de professores.

Palavras-chave: Política de formação docente; formação política; Pibid.

Abstract: The article presents research results that analyze the Institutional Program of the Initiation to Teaching Scholarship (PIBID), focusing on how the university professors who work in the Program conceive and evaluate it as a teacher educational policy. The results of the qualitative study point to the positive aspect of the approximation between university and school as collaborative learning spaces, but they indicate problems. Among them, structural difficulties, high turnover of the graduates and the limitations related to the political formation of the undergraduates. It concludes that the PIBID, as a complementary policy, can become a reproducer of the current problems in the field of teacher training.

Keywords: Teacher training policy; political formation; PIBID.

Resumen: El artículo presenta resultados de investigación que analizan el Programa Institucional de Becas de Iniciación a la Docencia, teniendo como foco el modo cómo los profesores universitarios, que actúan en el programa, lo conciben y evalúan como política de formación docente. Los resultados del estudio cualitativo resaltan como aspecto positivo el acercamiento entre universidad y escuela como espacios colaborativos de formación, pero señalan problemas, 
entre los cuales, dificultades estructurales, alta alternancia de los académicos y las limitaciones relacionadas a la formación política de los académicos. Se concluye que el Pibid, como política complementar, puede convertirse en reproductor de las actuales molestias en el campo de la formación de profesores.

Palabras clave: Política de formación docente; formación política; PIBID.

\section{INTRODUÇÃO}

A preocupação com a formação e a profissionalização docente consiste em um dos pontos fortes do cenário educacional internacional. Nas últimas décadas, foram produzidos inúmeros relatórios internacionais, artigos científicos, teses de doutoramento, discursos políticos, nos quais se nota um "consenso discursivo" sobre a necessidade de redefinir os processos de formação de professores tendo em vista uma efetiva mudança nas práticas escolares, de modo a responder aos inúmeros desafios da complexa sociedade do século XXI (NÓVOA, 2009).

Nesse "consenso discursivo" presente no conjunto de materiais produzidos em diversas instâncias internacionais, notam-se alguns princípios norteadores das políticas voltadas para assegurar a aprendizagem docente e o desenvolvimento profissional dos professores:

Articulação da formação inicial, indução e formação em serviço numa perspectiva de aprendizagem ao longo da vida; atenção aos primeiros anos de exercício profissional e à inserção dos jovens professores nas escolas; valorização do professor reflexivo e de uma formação de professores baseada na investigação; importância das culturas colaborativas, do trabalho em equipa, do acompanhamento, da supervisão e da avaliação dos professores, etc. (NOVOA, 2009 p. 13).

O autor adverte que o fato de termos construído um discurso coerente $\mathrm{e}$, em muitos aspectos, consensual não significa que tenhamos conseguido fazer aquilo que dizemos, pois a inflação retórica sobre os professores e sua formação não é acompanhada por uma política de valorização do magistério e de sua autonomia profissional; ao contrário, o que se percebe é uma ampliação dos controles estatais sobre a prática docente. Nesse sentido, o autor afirma ser necessário

Construir políticas que reforcem os professores, os seus saberes e seus campos de actuação, que valorizem as culturas docentes, e que não transformem os professores numa profissão dominada pelos universitários, pelos peritos ou pela "indústria do ensino" (Idem, p. 16). 
No Brasil, em consonância com o debate internacional, o trabalho docente também tem sido alvo de constantes debates e discussões que ressaltam a necessidade de mudanças nos processos de formação inicial e continuada de professores, tendo em vista a construção de novos horizontes no campo educativo. Entre as questões amplamente discutidas, destaca-se a crítica ao distanciamento existente entre o que a universidade ensina e aquilo que é vivenciado na instituição escolar. A complexidade do trabalho educativo exige a construção de práticas colaborativas na formação dos professores, partindo do pressuposto de que a escola se configura como o espaço de formação, reflexão e análise partilhadas das práticas educacionais.

Nesse cenário, foi criado, em 2007, o Programa Institucional de Bolsa de Iniciação à Docência (Pibid), iniciado em 2008, que vem consolidando-se cada vez mais como parte integrante no processo formativo dos estudantes e, sobretudo, estimulando parcerias entre universidades e escolas básicas.

Dentre as principais contribuições a que se dispõe o Programa, destacase a possibilidade de inserção dos licenciandos - aluno bolsista - na escola básica, de modo a observar, refletir e atuar naquele espaço junto aos demais educadores. A proposta é de que a universidade tenha a oportunidade de ampliar as dimensões do processo de formação de professores, que não mais se restringe aos limites de seus muros, mas agrega a dinâmica da escola pública como espaço formador, campo fecundo para que os licenciandos consolidem a práxis educativa.

Por outro lado, o Programa objetiva contribuir para que o professor supervisor - docente participante do Pibid que atua na escola básica - volte-se para sua própria prática e a confronte com as discussões teóricas realizadas em grupo, perscrutando subsídios para sua atuação, ampliando, dessa forma, a construção de saberes e experiências no cotidiano escolar. Assim, o Pibid tem como foco a formação docente, tanto inicial (aluno bolsista) como continuada (supervisores). Trata-se, portanto, de um programa de ação de certo modo coerente com o "consenso discursivo" construído sobre a formação de professores na medida em que os objetivos propalados deixam entrever a ideia de que "nossas propostas teóricas só fazem sentido se forem construídas dentro da profissão, se forem apropriadas a partir de uma reflexão dos professores sobre o seu próprio trabalho" (NÓVOA, 2009, p. 18).

Como política complementar de formação de professores em franco processo de expansão em nível nacional, faz-se necessário aguçar o olhar sobre o Pibid, buscando evidenciar seus limites e possibilidades. Com esse objetivo, este estudo buscou analisar o modo como o concebem os professores universitários 
que atuam como coordenadores de área $(\mathrm{CA})^{1}$ no Pibid e como o avaliam enquanto política pública de formação de professores. Além disso, busca investigar os desdobramentos da implantação e do desenvolvimento do Programa, no sentido de perscrutar a formação política que oferece aos envolvidos.

A investigação - que integra um conjunto de estudos e pesquisas sobre políticas educacionais e de formação de professores - concentra-se nas ações do projeto institucional Pibid elaborado pela Universidade Federal de Uberlândia (UFU), desenvolvidas por meio dos subprojetos na Faculdade de Ciências Integradas do Pontal (Facip), campus do Pontal, na cidade de Ituiutaba-MG.

A problematização central deste estudo direciona-se para a seguinte questão: como os professores universitários que atuam no Pibid concebem e avaliam o Programa enquanto política pública para subsidiar a formação inicial dos licenciandos? Para a coleta de dados, foi utilizada a técnica da entrevista semiestruturada, "na qual o entrevistado tem a possibilidade de discorrer sobre o tema em questão sem se prender à indagação formulada" (MINAYO, 2011, p. 61). As entrevistas foram realizadas com nove dos quinze coordenadores de área que participam do Programa. A análise dos dados tomou como referência o cotejamento das propostas do Programa; tendo como suporte as referências teóricas utilizadas, buscamos evidenciar as proposições e as contradições existentes entre a proposta e sua concretização.

\section{A PARTICIPAÇÃO DA UNIVERSIDADE FEDERAL DE UBERLÂNDIA NO PIBID}

O Programa Institucional de Bolsa de Iniciação à Docência, foi criado em 2007 e iniciou sua implementação em 2008. Por meio do Decreto no 7.219, de 24 de junho de 2010 (BRASIL, 2010), o Programa foi ampliado, estendendose às instituições de ensino superior (IES) de todo o território nacional. $\mathrm{Na}$ Universidade Federal de Uberlândia (UFU) o Pibid se iniciou em 2008 e está na quarta edição, como mostra o quadro a seguir:

1 São os professores universitários que assumem a coordenação de um subprojeto do Pibid para desenvolver uma área específica do curso de formação de professores a que pertencem. 
Quadro 1: Edições do Pibid-UFU, 2008-2013

\begin{tabular}{|c|c|c|c|c|c|c|c|c|c|c|}
\hline \multirow{2}{*}{ Ano } & \multicolumn{2}{|c|}{$\mathrm{CL}$} & \multicolumn{2}{|c|}{ C } & \multicolumn{2}{|c|}{$S$} & \multicolumn{2}{|c|}{$\mathrm{L}$} & \multicolumn{2}{|c|}{ EEB } \\
\hline & Udia & Itba & Udia & Itba & Udia & Itba & Udia & Itba & Udia & Itba \\
\hline 2008 & 4 & - & 4 & - & 10 & - & 53 & - & 5 & - \\
\hline 2009 & 7 & 4 & 7 & 4 & 16 & 8 & 144 & 80 & 8 & 4 \\
\hline 2011 & 16 & 7 & 16 & 7 & 29 & 12 & 225 & 98 & 17 & 7 \\
\hline 2013 & 21 & 8 & 40 & 15 & 82 & 32 & 583 & 212 & 39 & 16 \\
\hline
\end{tabular}

Legenda: CL, Cursos de Licenciatura; C, Coordenadores; S, Supervisores; L, Licenciandos; EEB, Escolas de Educação Básica; Udia, Uberlândia; Itba, Ituiutaba.

Fonte: Projetos institucionais Pibid-UFU disponíveis em: http://www.pibid.prograd.ufu.br.

Nota-sem a cada edição, o aumento progressivo de sujeitos, cursos e instituições escolares envolvidas no Programa, tanto nos campus de Uberlândia como no campus de Ituiutaba (Facip). O atual projeto da UFU conta com a participação de 982 sujeitos envolvidos, sendo uma coordenadora institucional, três coordenadores de gestão, 55 coordenadores de área, 114 supervisores e 795 licenciandos. Estão envolvidos 29 cursos de licenciatura e 55 escolas de Educação Básica, com atendimento da Educação Infantil até o Ensino Médio e também às modalidades de ensino e diversidades culturais.

Esse aumento expressivo do número de bolsas concedidas desde o início do Programa faz parte da política de investimento da Capes, que se propôs rever as normas a fim de expandi-lo. A meta a ser atingida seria a concessão de cem mil bolsas em 2014. E chegou-se próximo disso, com a adesão de 90.254 bolsas no final do ano (BRASIL, 2013). De acordo com o atual Projeto Institucional, as unidades acadêmicas que o compõem poderão fortalecer-se, estabelecendo diálogos sobre a formação e a escola pública por meio de uma construção coletiva e compartilhada.

Como política complementar de formação inicial de professores em franco processo de expansão em nível nacional, traduzida como um fenômeno de possibilidades, já é possível fazer questionamentos a respeito dos impactos do Programa na UFU: o Pibid tem oportunizado aos licenciandos reflexões significativas sobre a ação docente e o trabalho escolar? A relação universidadeescola tem promovido mudanças significativas a partir dessa convivência? Os princípios de formação que sustentam as propostas dos subprojetos efetivam-se na prática? A "parceria" da União com os demais entes federados tem garantido a plena execução do Programa, com condições favoráveis? O Pibid tem promovido mudanças que valorizam a cultura docente, tanto inicial (aluno bolsista) como 
continuada (supervisores), ou se baseia no imediatismo para resolver problemas nos dois âmbitos? O Programa tem contribuído para a oferta da formação política necessária a uma atuação crítica do sujeito na escola?

Muitos desses questionamentos remetem à necessidade de realização de outras investigações. No entanto, os gestores dos subprojetos das instituições formadoras apresentam algumas respostas que podem suscitar reflexões sobre as políticas de formação de professores.

\section{DIÁLOGOS COM OS PROFESSORES UNIVERSITÁRIOS SOBRE AS AÇÕES DO PIBID}

A abordagem que direcionou as discussões deste item volta-se para a problematização das concepções e princípios que orientam as ações e as estratégias empreendidas por coordenadores de área (CA) do Pibid/Facip/UFU, assim como a investigação sobre que avaliação fazem esses sujeitos do Programa a partir de suas experiências no exercício de suas funções. Para tanto, procedeuse à análise das entrevistas semiestruturadas, realizadas com nove dos quinze coordenadores de área, que também são autores dos subprojetos que coordenam na instituição. Para preservar o anonimato dos sujeitos entrevistados, seus nomes serão representados pelas letras iniciais de "coordenador de área" - CA - seguidas de um numeral, de 1 a 9. Tomamos como referência duas categorias de análise que orientaram o roteiro de perguntas para a entrevista: 'concepções e atribuições do Pibid' e 'avaliação que fazem do Programa'.

Como ponto de partida, perguntamos aos professores o que justificou a elaboração de uma proposta para o subprojeto do Pibid. Os depoentes foram unânimes em considerar o Programa como nova e promissora possiblidade de promover a formação docente, como verificamos em algumas de suas falas: "oferecer uma formação pedagógica melhor para os licenciandos (CA7); "Melhorar a qualidade do professor em exercício na escola (CA1)"; "Possiblidade de melhorar a relação com a escola e, com isso, melhorar os trabalhos com o estágio supervisionado (CA2)"; Por acreditar que a partir do Pibid os alunos do curso teriam oportunidades diferenciadas para sua formação (CA3); "Para dar essa formação pedagógica, não só teórica, mas prática, porque o curso não dá conta (CA4)".

Os entrevistados concebem o Programa como um colaborador para potencializar o trabalho que já realizam. Reconhecem que a formação oferecida pelo curso apresenta lacunas quanto à oferta dos estágios supervisionados, à 
articulação entre teoria e prática e à ausência de potencialização da formação pedagógica, além de constatar a falta de preparo dos professores da Educação Básica, que se beneficiam por meio de formação continuada.

Quando perguntamos sobre as contribuições do Pibid para a formação dos futuros professores, as respostas dos depoentes apontam para um conjunto diverso de possibilidades relacionadas à: "Vivência de experiências metodológicas diferenciadas" (CA9); “Articulação da teoria - 'aprendida' na universidade - e da prática - vivenciada na escola (CA3)"; "Incentivo à docência e valorização do magistério (CA8)". Todos os entrevistados destacaram, de alguma forma, a importância da presença do licenciando na escola.

A efetivação do trabalho colaborativo entre universidade e escola se configura em grande desafio a ser enfrentado, pois a simples presença do licenciando na escola não garante essa interação, podendo manter a tradicional segregação entre os dois campos distintos de formação: a universidade como lócus da teorização e a escola o lócus da prática. Sobre essa questão, são pertinentes as observações de Pereira (1999)

\footnotetext{
Não basta o domínio de conteúdos específicos ou pedagógicos para alguém se tornar um bom professor, também não é suficiente estar em contato apenas com a prática para se garantir uma formação docente de qualidade. Sabe-se que a prática pedagógica não é isenta de conhecimentos teóricos e que estes, por sua vez, ganham novos significados quando diante da realidade escolar (p. 114).
}

Uma importante questão sinalizada pelos entrevistados consiste na função do supervisor como coformador do licenciando, valorizando os saberes e a cultura do professor que atua na escola básica:

\footnotetext{
Com o Pibid, o professor da Educação Básica passa a ser compreendido como um coformador, alguém dotado de um saber experiencial e, por isso, responsável pela formação dos futuros professores; os licenciandos têm a oportunidade de acompanhar aulas e aprender conteúdos de forma diferenciada da que vivenciam na graduação (CA2).
}

A propósito dessa questão, Nóvoa (2009) sublinha a importância de delimitar um lugar predominante na formação dos futuros docentes aos professores que atuam na escola básica para reforçar o sentimento de pertença e identidade profissional essencial para efetivação dos processos de transformação da realidade escolar. Para o autor, a exemplo dos médicos e hospitais escolares que atuam de modo efetivo na formação inicial, "é preciso passar a formação de professores para dentro da profissão", concedendo aos professores mais experientes um papel central na formação dos mais jovens, pois não haverá “nenhuma mudança 
significativa se a 'comunidade dos formadores de professores' e a 'comunidade dos professores' não se tornarem mais permeáveis e imbricadas” (p. 16).

Apesar de todos os sujeitos asseverarem a importância do Pibid, na avaliação que fizeram foram apontados muitos problemas: nas escolas, condições físicas, materiais e estruturais desfavoráveis; nos subprojetos, alta rotatividade dos licenciandos; absoluta falta de integração das ações do Pibid com as outras áreas do curso. "Entre os demais professores do curso, verbalmente, o Pibid até chega a ser reconhecido como significativo apoio na formação dos alunos, mas não se envolvem" (CA5).

Um aspecto destacado pelos entrevistados é que, de certo modo, o Programa se apresenta restritivo e excludente, na medida em que não atende a todos os licenciandos, o que acaba gerando uma divisão no curso:

'De um lado, com status de superioridade, os 'pibidianos', que recebem um tipo de formação; de outro, os alunos restantes do curso de licenciatura, que não participam do Programa e recebem outro tipo de formação [...]. Igualmente, apenas um supervisor é selecionado para participar do Programa na escola" (CA7).

Outro aspecto destacado pelos depoentes é o desacerto nos repasses de recursos financeiros decorrente da forma de gestão dos recursos e da falta de articulação com instâncias superiores. A escassez ou contingenciamento dos recursos não facultam a realização das ações e atividades planejadas em cada subprojeto, o que desmobiliza e desmotiva os coordenadores, supervisores e seus alunos:

O problema está na gestão dos recursos e na forma como tem sido conduzida. Isso é muito frustrante, porque você gera uma expectativa na escola, nos alunos que participam. Estamos começando 2015, e o que foi previsto para 2014 ainda não se concretizou. Até acredito que faça parte da política nacional da Capes não ter repassado os recursos, só que talvez a distribuição pudesse ter sido diferente. Nós recebemos uma parcela de oito que deveriam ter sido pagas em 2014. (CA8).

Indagados sobre a estratégia do governo de implantar um programa de revitalização da formação inicial de professores como garantia da melhoria da qualidade do ensino na Educação Básica no Brasil, todos os depoentes enalteceram as vantagens do Pibid, mas o assumiram como política isolada e desprovida de contextualização, uma política de complemento que não se legitima:

Claro que não! Primeiro, porque não é com políticas alternativas que vamos dar conta de mudar a realidade da educação brasileira. Segundo, porque oferecer a tão alardeada "escola pública, gratuita e de qualidade para todos" passa por uma profunda reestruturação do sistema de ensino: condições de trabalho, plano de 
carreira, política salarial, infraestrutura, entre outros. Como diz Mészáros, é contraditório procurarmos uma reforma sistêmica dentro do próprio sistema de capital. Ele assegura que só teremos uma alternativa diferente para a educação se nós rompermos com a lógica do capital. Conseguiremos? É o nosso maior desafio (CA5).

As questões observadas pelo entrevistado remetem às mazelas da Educação Básica brasileira regida pela lógica da Nova Gestão Pública (NGP) implementada a partir dos anos 1990 em um contexto de reformas neoliberais - que engendrou uma forma de organização do ensino fundamentada na competição e na busca de eficiência, transformando a educação em mercadoria. As políticas educacionais brasileiras trazem em seu bojo, desde então, propostas de educação desenvolvidas por agências multilaterais ${ }^{2}$ instituições que exercem grande influência nas diretrizes governamentais dos países em desenvolvimento - que concebem a educação como "serviço prestado" e o ensino como forma de comércio (DOURADO, 2002).

O desenvolvimento desse modelo de gestão caracterizado pela adoção dos critérios da economia privada na gestão da coisa pública coloca em risco os processos de expansão de direitos sociais pela estratégia do governo de desresponsabilização das políticas sociais, numa clara intenção de minimização dos direitos dos cidadãos pelo chamado neoliberalismo vigente e cada vez mais crescente (OLIVEIRA, 2015).

Ao mesmo tempo em que se desresponsabiliza o Estado, aumentamse as estratégias de controle, utilizando-se como mecanismos regulatórios a elaboração de indicadores de desempenho e avaliação de resultados pautados na lógica mercadológica de incentivo à concorrência e à competitividade entre as instituições escolares.

Em decorrência da incorporação das orientações da NGP na área da educação, o ambiente escolar é invadido pelo que Afonso (2014) denomina "avaliocracia", que consiste na configuração de um campo saturado de avaliações: das escolas, dos alunos, dos professores, dos sistemas de ensino, dos programas e das próprias políticas educacionais.

Esse processo leva gestores e professores à busca obstinada por melhores resultados que são divulgados em rankings nacionais e internacionais, independentemente das condições de trabalho às quais esses profissionais estão submetidos. Os professores e gestores das escolas sofrem, nesse processo, com

\footnotetext{
2 Organização para a Cooperação e Desenvolvimento Econômico (OCDE), Unesco, Banco Mundial, Banco Interamericano de Desenvolvimento, Fundo Monetário Internacional (FMI, Comissão Econômica para a América Latina e o Caribe (CEPAL), o Fundo das Nações Unidas para a Infância (UNICEF) e o Programa das Nações Unidas para o Desenvolvimento (PNUD), entre outros.
} 
o sentimento de frustração e de culpabilização quando os resultados não são satisfatórios. Essa estratégia de responsabilização das instituições educacionais pela melhoria da qualidade e pelo desempenho dos alunos gera, ainda. a intensificação do trabalho dos profissionais da educação, na medida em que, pela lógica meritocrática, o recebimento de recursos financeiros está condicionado aos índices alcançados pela instituição.

Vemo-nos diante de desafios de toda ordem, e, por isso, significativas mudanças nas condições de trabalho dos profissionais da educação se fazem necessárias quando se implementam políticas de formação docente tendo em vista a melhoria da Educação Básica. Nessa perspectiva, é preciso considerar que o trabalho docente não se detém especificamente nas questões de ensino e aprendizagem, mas implica o processo formativo do sujeito que envolve questões sociais, requer uma inserção cultural e assume uma dimensão política. Dessa forma, o modo como o licenciando é formado na universidade ressoará na forma como ele irá atuar como docente na Educação Básica. Formar o cidadão capaz de perceber de forma crítica os problemas decorrentes da sociedade capitalista contemporânea - marcada pela ideologia neoliberal - para que ele não seja subjugado à condição de subordinação, implica ter como referência professores com essa mesma concepção. O professor medíocre formará alunos medíocres. Por isso, é preciso questionar o modo como os cursos de formação de professores conduzem essa formação política dos futuros professores.

Perguntamos então aos professores se o acesso facilitado à escola básica que vinha sendo feito por meio do Pibid, aliado às vivências da vida acadêmica, contribuía com a formação política dos futuros professores. As respostas demonstram que os professores enfatizaram as limitações do Programa quanto à oferta de formação política na medida em que este restringe suas ações à execução de atividades pontuais para a resolução de problemas do momento:

Como política púbica, o Pibid não pode ser visto com um olhar ingênuo. Primeiro, porque ele se configura como uma política de caráter imediatista, que desenvolve ações pontuais para resolver problemas pontuais. Esse imediatismo desconsidera a visão do todo, aliena o aluno e o impede de fazer uma reflexão crítica da sua formação e do que o espera depois de formado. Segundo, porque a profissão docente não se resume em resolver problemas pontuais, mas está sujeita às diversas variáveis construídas historicamente no País, tais como condições inadequadas de trabalho, desvalorização do exercício docente e do papel do professor na sociedade, ausência de um plano de carreira digno e salários pouco atrativos (CA1).

O Pibid tem oportunizado uma relação saudável entre universidade e escola básica. [...]. No entanto, as ações efetivamente desenvolvidas pelos alunos se restringem a dinamizar a metodologia das aulas. Não há uma problematização do contexto e a prática acaba por encerrar-se em si mesma (CA8). 
Os professores apresentaram também uma descrença em relação à formação de seus alunos, atribuída à lógica precária de organização do sistema de ensino, que resulta na má formação da Educação Básica e no desinteresse do próprio aluno:

Vivemos num momento de oportunidade ímpar com o Pibid. Entretanto, o anseio de buscar o alcance de números nos torna muito volúveis e suscetíveis a cair nessa armadilha de analfabetos funcionais. Eu tenho alunos que não sabem interpretar, não conseguem escrever, e eles chegaram assim na Universidade (CA2).

Outra questão importante que evidencia o nível de despreparo dos alunos é que tenho que pegar leve nas cobranças, porque se eu cobro, na semana seguinte o aluno não aparece. Ai vai ter um subprojeto sem alunos? E essa não é uma realidade só minha, sejamos bem sensatos. E esses números são bons para a educação? Tem como substanciar uma formação política com os alunos? Acredito que não. (CA2).

Observamos uma séria crítica dos professores coordenadores no que se refere à organização do sistema de ensino, que produz políticas de complemento no ensino superior sem ter tido o cuidado de alicerçar a base da formação, o Ensino Fundamental e o Ensino Médio. Esta forma de legislar sobre a educação prefigurando um trabalho desarticulado do professor reforça o que expressa o pensamento de Veiga e Quixadá-Viana (2010) quando afirmam que, nesse contexto, é marcante a "transmissão rápida de conhecimentos, habilitação relâmpago de professores [...] dosando e quantificando resumidamente o conhecimento até chegar à informação técnico-instrumental de um que faz̧er acrítico e alienado" (p. 17). Mais uma vez reforça-se a política de supressão feita pelo Estado neoliberal.

Portanto, seguramente não serão essas políticas alternativas de caráter imediatista e desprovidas de formação política que mudarão efetivamente o atual cenário educacional do Brasil. A mudança requer uma transformação social como via para a reestruturação da sociedade. Na concepção de Mészáros (2008) "A transformação social emancipadora radical requerida é inconcebível sem uma concreta e ativa contribuição da educação no sentido amplo (p. 76). Essa mudança também passa pela formação dos profissionais da educação, sujeitos historicamente constituídos, que se identifiquem com o trabalho que realizam e nele se reconheçam. 


\section{CONSIDERAÇÕES FINAIS}

Verificamos que, pela ótica dos professores coordenadores de área, o Pibid é visto como oportunidade potencial de aproximar a universidade e a escola. Sem dúvida, é essa uma das mais positivas estratégias do Programa no sentido do enfrentamento de um problema histórico nos modos de organização da profissão docente, marcada por fortes tradições individualistas, na medida em que possibilitam a construção de culturas colaborativas entre o mundo profissional e o mundo universitário nos processos de formação inicial de professores.

O desafio que temos pela frente é romper com uma formação pautada em uma racionalidade técnica que se restringe aos muros escolares e não consegue dar respostas úteis aos futuros professores no que toca à complexa realidade que irão enfrentar. Hoje, talvez mais do que nunca, impõe-se a necessidade de uma formação política como referência para um processo significativo da formação e valorização dos professores, pois a força de uma profissão se define, em grande parte, por sua capacidade de participação política nas sociedades contemporâneas.

Programas como o Pibid motivam algumas mudanças, especialmente no que diz respeito a novas metodologias/didáticas, mas a melhoria da qualidade da Educação Básica exige alterações das condições existentes nas escolas. Essa forma de fazer política seria desnecessária se houvesse o compromisso do Estado em assumir a formação docente como obrigação social, por meio da reestruturação dos cursos de licenciatura e, aliado a isso, a oferta de justas políticas no que se refere a salário e carreira, com condições favoráveis de trabalho para todos os profissionais da educação.

\section{REFERÊNCIAS}

AFONSO, A. J. Questões, objetos e perspectivas em avaliação. Avaliação: Campinas; Sorocaba SP, nº 2, julho p. 487-507, 2014.

\section{BRASIL. Pibid - Programa Institucional de Bolsa de Iniciação à Docência} [online]. Brasília: MEC, 2008. Disponível em: <http://www.capes.gov.br/ educacao-basica/capespibid>. Acesso em: 6 fev. 2015.

Decreto $\mathbf{n}^{\mathbf{0}}$ 7.219, de 24 de junho de 2010. Dispõe sobre o Programa

Institucional de Bolsas de Iniciação à Docência (Pibid). Brasília: Imprensa Nacional, 2010. 
. Relatórios e dados [online]. Brasília: MEC, 2013. Disponível em: <http://www.capes.gov.br/educacao-basica/capespibid/relatorios-e-dados $>$. Acesso em: 6 fev. 2013.

DOURADO, L. F. Reforma do Estado e as políticas para a educação superior no Brasil nos anos 90. Educação e Sociedade, v. 23, n. 80, p. 234-252, set. 2002.

MÉSZÁROS, I. A educação para além do capital. São Paulo: Boitempo, 2008.

MINAYO, M. C. de S. Pesquisa social: teoria, método e criatividade. $30^{a}$ ed. Petrópolis: Vozes, 2011.

NÓVOA, A. Professores: Imagens do futuro presente. Lisboa: Educa, 2009.

OLIVEIRA, D. A. Nova Gestão Pública e governos democrático-populares: contradições entre a busca da eficiência e a ampliação do direito à educação. Educação \& Sociedade, Campinas, nº 132, p. 625-646, jul.-set., 2015

PEREIRA, J. E. D. As licenciaturas e as novas políticas educacionais para a formação docente. Educação \& Sociedade, Campinas, nº 68, p. 109-125, dez. 1999.

UNIVERSIDADE FEDERAL DE UBERLÂNDIA. Projeto Institucional do Programa Institucional de bolsa de Iniciação à Docência - Pibid. 2008-2013.

Disponível em: <http://www.pibid.prograd.ufu.br/?q=ProjetoInstitucional $>$. Acesso em: $1^{\circ}$ fev. 2015.

VEIGA, I. P. A.; QUIXADÁ VIANA, C. M. Q. Formação de professores: um campo de possibilidades inovadoras. In: VEIGA, I. P. A.; SILVA, E. F. (orgs.). A escola mudou. Que mude a formação de professores! Campinas, SP: Papirus, 2010. p. 13-34.

VALÉRIA MOREIRA REZENDE é Doutora em Educação pela Pontifícia Universidade Católica de São Paulo. Atualmente é docente pesquisadora do Curso de Pedagogia da Universidade Federal de Uberlândia - FACIP. Trabalha com as disciplinas: Currículo, Planejamento Educacional, Prática Educativa e Estágio Supervisionado e Educação e Transformação Social. Credenciada no Programa de Pós-Graduação em Educação da Universidade Federal de Uberlândia, na Linha de Pesquisa Estado, Políticas e Gestão da Educação. Líder do Grupo 
de Estudos e Pesquisas em Política, Formação Docente e Práticas Educativas - GEPPOPE. Desenvolve pesquisas em Políticas Educacionais com ênfase nos seguintes temas: Planejamento e Práticas Educativas, Formação/Trabalho Docente e Currículo e o Trabalho Pedagógico. E-mail: valeria.rezende@ufu.br

ROGÉRIA MOREIRA REZENDE ISOBE possui Graduação em Pedagogia pela Universidade Federal de Uberlândia (2001), Mestrado (2004) e Doutorado (2008) em Educação pela Pontifícia Universidade Católica de São Paulo. Professora Adjunta do Departamento de Educação da Universidade Federal do Triângulo Mineiro (UFTM). Desenvolve atividades de ensino nos cursos de Licenciatura da UFTM bem como projetos de extensão e pesquisa com foco nos seguintes temas: História da Educação, Cultura e Educação e Políticas Educacionais voltadas para o trabalho docente, reconhecendo o caráter essencialmente histórico dos processos que envolvem a temática. E-mail: rogeriaisobe@gmail.com.br

Recebido em setembro de 2016 Aprovado em outubro de 2016 